\title{
Integrating Just in Time Theory, Resource Based View Theory, and Rational Choice Theory in Enhancing Managements' Efficiency
} \author{
Nigeria \\ *Corresponding Author \\ Osinowo, O

\section{Article History} \\ Received: 23.01.2021 \\ Accepted: 09.02.2021 \\ Published: 14.02.2021
}

Asikhia, $\mathrm{A}^{1}$, Osinowo, $\mathrm{O}^{2 *}$, Kassim, S. K ${ }^{2}$

${ }^{\mathrm{T}}$ Business Administration and Marketing Department, Babcock University, Ilishan, Remo, Ogun State, Ilishan-Remo,

${ }^{2}$ Accounting Department, Babcock University, Ilishan, Remo, Ogun State, Ilishan-Remo, Nigeria

\begin{abstract}
The result of management efficiency estimate is essential for all organization because it actively influences existing socio-economic status and foster their growth. Research has shown that using more than one theory would help to gain deep perspectives and detailed knowledge of the practice. This study constructs a theoretical framework by integrating three theories to explain Managements' efficiency. The study explains that theories complement each other and do not compete. Integrating Just in Time Theory in Managements' efficiency helps organization to build competitive edge, minimal waste and financial increase. This study also reveals that any organization that integrates Resource Based View Theory will maintain competitive advantage over its competitors through implementation of distinct resource. Rational Choice Theory assists the management to make the best-expected decision, after considering several alternatives. This study concludes that Just in Time Theory, Resource Based View Theory and Rational Choice Theory are valuable and enhances managements' efficiency if rightly integrated.
\end{abstract}

Keywords: Efficiency, Just in Time, Management, Rational Choice, Resource Based View.

\section{INTRODUCTION}

The efficiency of management in the organization is the primary resource for enhancing the final results of its operations. The conceptualization, production and enhancement of theoretical and methodological methods for the successful practical management of an organization is an important way of improving management in relation to its economic, industrial, technical and organizational processes [1].

Moreover, it is necessary to perform a comprehensive examination and analysis of the existing theoretical structure, as external and internal developments in the organization's competitive environment inevitably lead to the introduction of new management efficiency assessment approaches. Management of any organization is, therefore, one of the most critical factors for determining its efficiency.

Tishchenko, Kizim, and Dogodailo [2] opined that as, there is a need to pay attention to the analysis of the practices that take place in the business environment as the influence of the external competitive market and the internal setting in which the organization works increases, as well as to build or enhance the methods that make it possible to appraise their influence on the overall management of the organization.

Scientific literature does not adequately research the problem of management efficiency assessment under modern socio-economic conditions. There is currently no universal understanding of the clear fundamental elements, metrics, and parameters that define the management efficiency of the organization.

Copyright (C) 2021 The Author(s): This is an open-access article distributed under the terms of the Creative Commons Attribution 4.0 International License (CC BY-NC 4.0) which permits unrestricted use, distribution, and reproduction in any medium for noncommercial use provided the original author and source are credited. 
Many scientists consider management efficiency, firstly, as the level of achievement of the goals, the set strategy, the speed and stages of the activity and growth of the organization's socio-economic, efficient, organizational or technological structures, the level of their organization and performance. In other words, the efficiency of managers is understood as equal and interrelated concepts to quality, productivity, success, stability and consistency.

Management efficiency is the output generated by a management team relative to the resources they manage and the expenses they incur.

Research has shown that management efficiency is dynamic and cannot be described from a single point of view, but instead involves a more integrated and flexible approach. Likewise, there is currently no universal understanding of the clear fundamental elements, measures, and standards that assess the management efficiency of the organization.

It is also important to note that in describing management efficiency, there is no approved theoretical perspective because there are a lot of disparities in the theoretical perspectives. Earlier research incorporates any theory or theories that they consider fit [3].

Besides, Deegan, Rankin, and Voght [4], proposed that using more than one theory would help to gain deep perspectives and detailed knowledge of the practice. Gray [5] has concluded that theories complement each other and do not compete. this study.

Therefore, Just in Time Theory, Resource Based View Theory, and Rational Choice Theory were integrated in

\section{THEORETICAL PERSPECTIVES OF MANAGEMENT EFFICIENCY}

This section reviews and discusses Just-in-Time Theory, Resource Based View Theory, and Rational Choice Theory. The discussion of each theory includes a general introduction and integrating the theory in management efficiency.

\section{JUST IN TIME THEORY (JIT)}

In 1970, JIT was propounded and enhanced by Taiichi Ohno. JIT has been harnessed in practice in many manufacturing organizations in Japan since it was proposed. Taiichi Ohno first developed JIT inside the Toyota production plants as a mode of meeting customer demands with slight interruption. JIT manufacturing, also referred to as JIT manufacturing or the Toyota Production System (TPS), is an approach specifically meant to minimize flow times in the production system together with supplier and consumer response times.

Schonberger [6] made the first JIT theory. He studied Toyota's case and proposed the transfer of Japanese approaches to manufacturing management to the US industry. JIT means producing with minimal waste [7]. Waste is taken in the most general context and involves both materials and time and energy. Originally, it applied to the manufacture of products to satisfy the demand of the consumer specifically, in time, quality and quantity, whether the consumer is the ultimate buyer of the commodity or another phase along the manufacturing line. In order to reduce costs and maximise income, JIT is the reduction of inventories.

Another study criticized JIT by suggesting that, with little advance notice, it is important to locate suppliers that can quickly supply resources. However, minimum order policies of suppliers can be a challenge, if small quantities of resources are being requested. Furthermore, when employed by factories that use JIT and versatile manufacturing methods, workers are at risk of indefensible jobs.

Moreira and Alves [8] argued that a limited percentage of firms have the requisite conditions to effectively introduce a JIT scheme, despite the strong understanding of the JIT concepts.

The JIT critical success factors were grouped by Mehra and Inman [9] into four groups; "management engagement, JIT development strategy, JIT vendor strategy, and JIT education strategy."

Singh and Garg [10] conducted extensive research and provided a detailed list of JIT components: master schedule, cellular development, computer-integrated manufacturing, continuous improvement, efficient communication, oriented factories, versatile workforce, JIT purchasing, high quality, design enhancement, flexibility of processes, simplification of products and processes, pull-controlled flow, re-setup time. 
Chu [11] noted that it is possible to characterize the effects of JIT implementation, either non-financial or financial, and concluded that JIT adoption is significant and that there is therefore no clear connection between JIT practices and performance indicators based on finance.

This is in contrast to Fullerton and McWatters [12], who reported that manufacturing firms that implement JIT will have financial increase and also argued that organizations that execute advanced levels of JIT should outpace their competitors that did not. Although, certain factors can hinder the method while others may lessen its effect on profitability. In addition, JIT practices discuss potential essential improvements in the corporate culture, structure of organizations, as well as improvements in their financial measures.

But there are also some constraints at the same time that can lead to unsuccessful implementation of JIT. Polito and Watson [13] argue that before any firms introduce JIT, it should be considered by experts; undergo consumer demand and economic considerations, logistics, organizational culture, rigid accounting and finance measures, and minor difficulties with suppliers should be considered. Singh and Garg [10] argue that it is critically dependent on this organizational change to preserve the continuous enhancement theory of JIT.

Singh and Garg [10] argue that it is critically dependent on this organizational change to uphold JIT's quality improvement theory.

\section{JIT ELEMENTS \\ Set-up Time}

Through many physical device improvements or programs, JIT goals are achieved. Ultimately, JIT aims at unit lot sizes and thus aims to minimize the setup time. There are consequences for decreasing the set-up times and variables involved in reducing various processes and set-up times.

\section{Quality Considerations}

The constant pursuit of improved quality by process changes is Quality Considerations. It is possible to decrease waste / rework and defects due to good product quality. This could be accomplished by adequate preparation and a system of quality management that covers all the staff on the shop floor.

\section{Manufacturing Cells}

JIT companies prefer to group their equipment for production. A group of machines is dedicated to the creation of a certain group of components. In order to reduce the travel distance and inventories between devices, the layout of equipment is designed. This means improved relations between workers and decreases the handling of materials.

\section{Supplier Buyer Co-ordination}

Traditionally, in Western countries, the relationships between producers and customers have been rather adversarial, as this is the key obstacle to the successful implementation of JIT. JIT delivery is a dedication to satisfying the customer and the manufacturer's timely needs. Thus, supply coordination and mutual support are crucial factors in JIT's operational performance. Although, some studies conclude that JIT has some constraints that can lead to ineffective implementation [14-16], argues that JIT is suitable for all companies.

\section{INTEGRATING JUST IN TIME THEORY}

As an organization moves to introduce JIT, multiple improvements in the relationships between different customer-supplier characteristics should be followed. By improving profits and return on investment through cost savings, inventory savings, and quality improvements, the implementation of JIT can provide a business with many benefits [10].

Although there are still doubts about the clear relevance of the implementation of JIT and the organization efficiency, there is no unanimous response based on the latest studies. Some research, such as Isaksson and Seifert [17], noted that there is a clear positive relationship, while others like Folinas and Shen [18], concludes that there is no correlation between JIT and organization efficiency. In a study carried out by Obermaier and Donhauser [19], they established that firms with smallest inventory have the poorest results and vice versa.

Hall [20] noted that JIT helps the implementing organization to manufacture high-quality goods with minimal production waste, and JIT represents a very significant opportunity for a corporation to have both strate gic and financial strength [3].

On cost and value fronts, businesses implementing a JIT orientation are seeking to build a competitive edge. Many JIT firms have been able to simultaneously lower their costs and increase their product quality by eliminating 
waste and non-value - added activities. JIT is increasingly seen as a necessity for competition in the global environment because of its impact [21].

Huson and Nanda [22] conclude that, in terms of increased profits, JIT actually generates firm value. JIT improves the efficacy of management by increasing inventory turnover and is considered to be the most noticeable JIT impact. Although the impact is marginal, JIT also improves performance, labor productivity, and decrease in production costs, better workforce, and flexibility in production.

In addition, Mould and King [23] analyzed six businesses that had implemented JIT and identified the following primary advantages: "cycle time reduction, work-in - progress, batch size and set-up time, as well as increased efficiency, customer responsiveness, and communication."

Gupta [24] recognized that the benefits of JIT are: "elimination (of waste and non-value - adding operations), reduction (of costs and lead / throughput time), increase (of efficiency, reliability productivity and customer responsiveness), integration (of functional business areas), versatility (of product mix) and improvement (of internal and external contact and participation of employees)." Gupta [24] also argued that these advantages further enabled firms that implement JIT to succeed effectively in the global environment.

Cannon [25] claimed that, while inventory has been used as a way to protect firms from demand instability, there are other critical success factors such as; "building closer and more cooperative partnerships with suppliers and consumers to optimize logistics and distribution networks and investing in better Information and Technology systems" [26].

With inventory playing a key role in the market and productivity of a corporation to satisfy customer service standards and seasonal demands, the ability of an enterprise to handle inventory to meet these demands can eventually influence the costs incurred by humans, taking into account various drivers, including exchange rates, sea and inland freight, government tax, and environmental factors.

A manufacturer must endeavor continuous improvement in order to stay competitive in an ever evolving and increasingly competitive market climate.

In addition, it must be known that if they do not find it, consumers do not wait any longer to buy a product; they will instantly purchase the available replacement for the product of a rival. Therefore, regardless of how often a firm attempts to compact its inventory levels in order to minimize costs and increase profitability, the firm must make sure that the competitor's product does not enter the market first; else, the measures may be battered. In other words, theories that encourage cost savings and increased profitability as a result of reducing inventory levels are valid, but to a certain degree sometimes. Therefore, JIT can be used to decrease inefficiency and eventually increase the bottom line of organizations, minimizes waste, reduce costs and maximize income if properly handled.

\section{RESOURCE BASED VIEW THEORY (RBV)}

The resource-based view theory centers on "the source and nature of organization strategic capabilities, which has an intra-organizational focus and argues that efficiency is a result of firm-specific resources and capabilities" [27, 28]. The foundation of the resource-based view is that efficient organizations will discover its future effectiveness on the improvement of distinct expertise, which may often be intangible in nature [29]. Furthermore, the organizations' ability to establish and sustain a profitable market position critically depends on the payment generating ability of its essential resources and competence [30].

Barney 2002 [31] posit that for any organization to preserve its competitive advantage and efficiency outcome, firms' specific resources and capabilities must be valuable, rare, hard and expensive to replicate by competitors. RBV also suggests that "an organization can be considered as a collection of, human resources, physical resources, and organizational resources" $[27,32]$

Madhanl 2010 [33] suggests that for any resource to provide competitive advantage and sustainable efficiency, 'VRIN' criteria must be achieved;

a) Valuable (V): There is no benefit of acquiring a resource if it does not augment value of the organization. Resources that provide strategic value to the firm and helps in utilizing market prospects or helps in curbing market threats are valuable.

b) Rare (R): Resources are said to be rare if it is complex to find among the current and potential contenders of the organization. For any resource to offer competitive advantage, it must be exclusive to the firm. Resources that can be 
easily acquired by numerous firms cannot offer competitive advantage, as they cannot plan and implement sole business strategy.

c) Imperfect Imitability (I): "Imperfect imitability means making copy or imitate the resources will not be feasible. Bottlenecks for imperfect imitability can be many viz., difficulties in acquiring resource, ambiguous relationship between capability and competitive advantage or complexity of resources enables an organization to have a competitive edge over another" Madhanl [33].

d) Non-Substitutability (N): Non-substitutability of resources denotes that competitors cannot achieve same efficiency by substituting resources with other alternative resources. When resource cannot be substituted by another alternative resource it means that such resource is non-substitutable.

RBV has led to rigorous theoretical framework for connecting the internal and external assets of the company [34]. RBV deals with an analysis in which their set of different resource endowments decides the competitive advantage of an organization and their business approach is organized based on these tools [35] while asset stability is another variable capable of capturing organization's competitive edge against other businesses.

RBV is a management structure which decides the strategic resources with the capacity to provide comparative advantage to any organisation. Such resources can be utilised by the organization in order to attain competitive advantage eventually. In an effort to identify assets and expertise with the aim to deliver exclusive competitive advantages, RBV centres management consideration on firm's internal resources. However, a firm may still lose persistent advantage eventually, especially if supply or demand terms change. The cost of resources could also inhibit them, if this nullifies or surpasses the maximum value that they produce [31].

Firms' competence is also a major factor which contributes to their value. Competence exemplifies what a firm does [36]. Prahalad and Hamel [37] termed competences as the collective knowledge that gives firms the capability to utilise their resources efficiently. This makes competences more important to a firm's competitive performance than the resources on which they are established [38] and hence valuable of certain consideration when evaluating the foundation of firm's efficiency.

Competence is usually distinct to each firm and inseparable from the firm $[39,40]$. Besides, this peculiarity in firm competence makes it rigid and hence challenging to apply in a competitive context [41].

\section{INTEGRATING RESOURCE BASED VIEW THEORY}

The resource-based view (RBV) highlights that firm's resources are the vital elements of competitive advantage and efficiency. RBV adopts two assumptions in evaluating sources of competitive advantage [27, 42]. First, firms within an industry may be diverse with respect to the collection of resources that they operate. Second, resource diversity may continue over time because the resources used to implement firms' strategies are not traded in the markets and are difficult to store and replicate. Uniqueness of any resource is considered essential for it contribute to a competitive advantage [31].

The argument goes "If all firms in a market have the same stock of resources, no strategy is available to one firm that would not also be available to all other firms in the market" [43]. For Barney [27] "if all the firms were equal in terms of resources there would be no profitability differences among them because any strategy could be implemented by any firm in the same industry". The fundamental logic holds that the sustainability of effects of a competitive position rests primarily on the cost of resources and capabilities that was utilized for implementing the strategy.

This theory has become essential due to its capacity to analyze the sources of a firm's competitive advantages both within and outside.

The company's unique internal innovation capability, with latent resource potential, increases a company's strategic position [27]. Therefore, the underlying emphasis of RBV is to recognize the unique attributes of the company's assets and balance them with the changing economic condition [44].

\section{RATIONAL CHOICE THEORY}

Rational Choice Theory was propounded in 1969 by Codd. The principle of rational choice has been presented as unrealistic because rationality is subjective, since in making decisions from time to time, people can be both rational and irrational [45]. In order to come to a decision, rational choice theory uses facts and evidence, interpretation, and a step-by-step process.

One of the four types of models of decision making is rational choice theory. Four different types of decisionmaking models proposed by Scott and Bruce [46] are: Rational, which is made up of rigorous and reasonable research; 
Intuitive, which is regarded by a dependence on hunches; Reliant, which is described by a quest for suggestion and direction from others; and Avoidant, which is portrayed by efforts to fully avoid decision-making [46].

The theory of rational choice is a more sophisticated form of decision-making model compared to other forms of decision-making model.

In the principle of rational choice, decision-makers prior to selecting a choice consider a variety of potential substitutions from various possible scenarios. These potential circumstances or scenarios are evaluated by probabilities, and the predicted end result for each option can be decided by decision makers. The final choice made by the decisionmaker will be the one offering the best-expectable outcome and with the highest outcome prediction [47].

The human personality is continually arraigned with options in a world full of choices that can be as fundamental as what to eat for breakfast or what to wear out to the party to determine what policies will have the best intended effect for national economic growth.

Rational choice theory is a context for social and economic behavior to be interpreted and correctly modelled [48]. The central principle of the theory of rational choice is that cumulative social action derives from the behavior of individual actors, each of whom makes their own choices. Consequently, the theory focuses on the determinants of individual decisions. The theory of rational choice then assumes that a person has preferences among the alternatives of choice available that allow them to state which chance they prefer [48, 49].

In deciding preferences and acting consistently in choosing the self-determined best course of action, the rational agent is presumed to take account of available knowledge, probabilities of events, and possible costs and benefits $[48,49]$. In economics, rational choice theory was developed and is said to constitute one of the three major theoretical paradigms in the social sciences.

Theories of rational choice are mainly normative theories. "A theory of rational choice" tell us what we can do to reach our goals as best as possible. In other words, a theory of rational choice may be seen as a "theory of advice" that advises individuals or, perhaps, individual groups on how best to accomplish goals, whatever they might be.

\section{INTEGRATING RATIONAL CHOICE THEORY}

The principle of rational choice allows the decision-maker to take decisions under certainty; the decision-maker understands all available alternatives and the potential result of each; the decision-maker understands all decision-making criteria; the decision-maker may choose between the alternatives the optinum choice and: the choice chosen can be adopted by the decision-maker. In the model, many processes are involved. Processes include: problem identification; creating alternative solutions; analyzing alternatives; selecting an alternative; enforcing the decision; and determining the efficacy of the decision made [50].

The method is an iterative process; the decision-maker may go back to the previous stage in case problems occur at any stage. As given by Rubinstein [51], this process can be summarized into three phases. The first step includes the study of alternatives' viability. The second stage includes focusing on the comfort of the alternative. However, prominent academics have accepted this hypothesis and argued for it to be valid. In the study of rational choice, for instance, Little [52] and Assian studies believed that the phylosophy of the system of rational choice was fair. He clarified that several of human beings' fundamental attributes, such as: goal-oriented, the need for personal and family welfare, the ability to obtain well-founded social and natural environment values, and the ability to make comparisons of many possible choices between benefits and costs, support their argument. Furthermore, in public decision-making, Leoveanu [53] recognized the importance of rational choice theory in dismissing many critiques that grow against the theory.

The theory of rational choice, however, has been heavily contested in literature. Simon [54] argued that decision-makers generally have limited experience, limited time and limited intellectual power. As a result, instead of using the optimizing or maximizing approach, a compromise or acceptable option (satisfactory) is made based on minimal knowledge [55]. Simon [54] continues his claim that as more and more data is collected, the cost of collecting information increases, so a compromised approach is safer for decision makers.

The final option selected by the decision-maker will be the one providing the best-predictable outcome and with the highest outcome prospects [47]. 


\section{THEORETICAL FRAMEWORK}

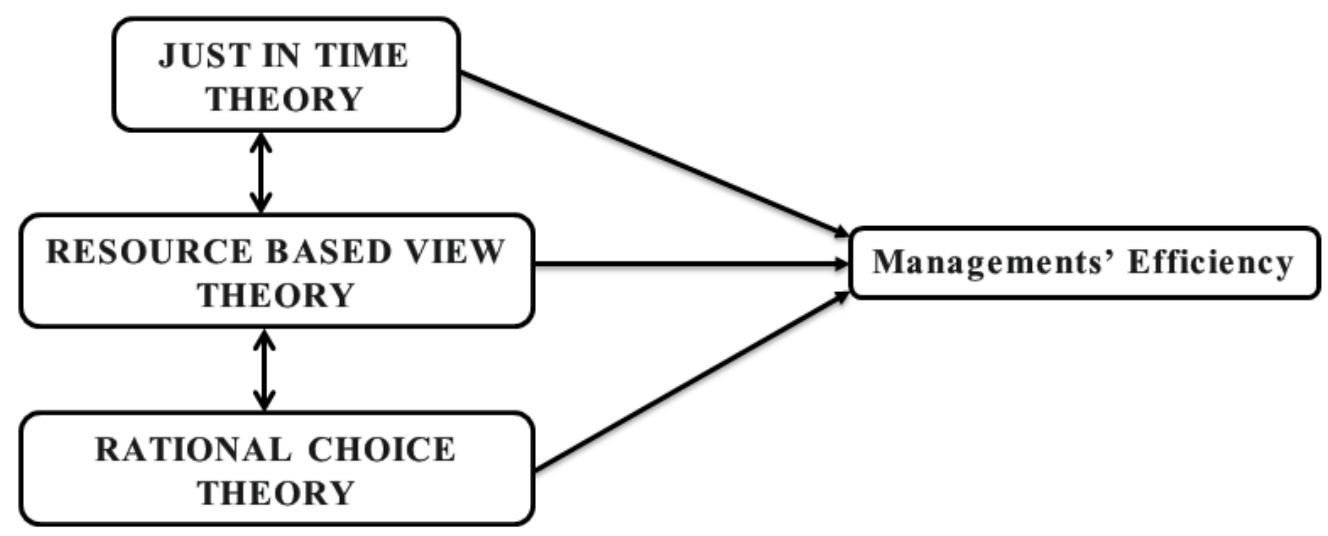

Fig-1

\section{CONCLUSION}

Management Efficiency is dynamic and cannot be defined from a single point of view, but needs a more integrated and scalable approach instead. Similarly, there is currently no common definition of the specific fundamental elements, metrics and principles that determine the organization's management performance. Earlier studies concluded that the greater the performance of management, the greater the profitability.

It is also important to remember that there is no approved theoretical perspective in explaining management efficiency since there are a number of differences in theoretical perspectives. Any hypothesis or theories that they consider fit [3] are included in earlier studies.

In addition, Deegan, Rankin, and Voght [4], indicated that it would be useful to obtain deep insights and detailed knowledge of the discipline by using more than one theory. Gray et al., [5] have concluded that theories complement and do not compete with each other. Therefore, Just in Time Theory, Resource Based View Theory, and Rational Choice Theory can be very advantageous when rightly integrated. Furthermore, the JIT helps organization achieve managements' efficiency by delivering of goods to consumer on time, in best quality and quantity. Also helps to reduce inventories, waste, costs and maximize income.

RBV assists organization to generate and maintain competitive advantages through the integration of rare, valuable and non-substitutable resources. Organizations that integrate RT make the best choice that will provide the bestexpected outcome and with the ultimate result projections [47].

\section{REFERENCES}

1. Cheymetova, V. A., \& Scherbakov, V. V. (2017). Methodological approaches to managerial efficiency evaluation of organization. Espacios, Venezuela, 38(48).

2. Tishchenko, A. N., Kizim, N. O., \& Dogodailo, Y. V. (2005). The economic effectiveness of enterprises. Monograph, Kharkiv:Inzhek, pp. 144.

3. Stephen N. Chapman (1989) Just-In-Time supplier inventory: an empirical implementation model, International Journal of Production Research, 27:12, 1993-2007, DOI: 10.1080/00207548908942669

4. Deegan, C. (2000). 'Firms' disclosure reactions to major social incidents: Australian evidence, Accounting Forum, 24(1), 101-130.

5. Gray, R. (1995). Corporate social and environmental reporting: A review of the literature and a longitudinal study of UK disclosure, Accounting, Auditing \& Accountability Journal, 8(2), 47-77.

6. Schonberger, R. J. (1982). Japanese manufacturing techniques. New York: The Free Press.

7. Cheng, T. C., \& Podolsky, S. (1996). Just-in-time manufacturing: an introduction. Springer Science \& Business Media.

8. Moreira, M., \& Alves, R. (2006). How far from Just-in-Time are Portuguese Firms? A Survey of its Progress and Perception, Working Papers (FEP), Universidade do Porto, 113, pp.1-23.

9. Mehra, S., \& Inman, R. A. (1992). Determining the critical elements in just-in-time implementation. Decision Sciences, 23(1), 160-174.

10. Singh, S., \& Garg, D. (2011). JIT system: concepts, benefits and motivation in Indian industries, International Journal of Management and Business Studies, 1(1), 26-30. 
11. Chu, E. (2007). Just-in-time implementation and financial performance: a review of survey studies, California Journal of Operations Management, 5(1), 38-44.

12. Fullerton, R. R., \& McWatters, C. S. (2001). The production performance benefits from JIT implementation, Journal of Operations Management, 19(1), 81-96.

13. Polito, T., \& Watson, K. (2006). Just-in-time under fire: the five major constraints upon JIT practices, Journal of American Academy of Business, 9(1), 8-13.

14. Krause, P., \& Keller, E. (1988). Bringing world-class manufacturing and accounting to a small company, Management Accounting, November, pp.28-33.

15. Karmarkar, U. (1989). Getting control of just in time, Harvard Business Review, 67(5), 122-131.

16. Sheridan, J. (1989). Just in time: two perspectives, Industry Week, pp.26-31.

17. Isaksson, O. H. D., \& Seifert, R. W. (2014). Inventory leanness and the financial performance of the firm, Production Planning \& Control, 25(12), 999-1014.

18. Folinas, D., \& Shen, C. (2014). Exploring links among inventory and financial performance in the agricultural machinery industry, International Journal of Food and Agricultural Economics, 2(4), 1-12.

19. Obermaier, R., \& Donhauser, A. (2012). Zero inventory and firm performance: a management paradigm revisited, International Journal of Production Research, 50(16), 4543-4555.

20. Hall, R. W. (1987). Attaining Manufacturing Excellence (Homewood, Ill.: Dow Jones-Irwin).

21. Germain, R., \& Dröge, C. (1997). An empirical study of the impact of just-in-time task scope versus just-in-time workflow integration on organizational design. Decision Sciences, 28(3), 615-635.

22. Huson, M., \& Nanda, D. (1995). The impact of just-in-time manufacturing on firm performance in the US. Journal of Operations Management, 12(3-4), 297-310.

23. Mould, G., \& King, M. (1995). Just-in-time implementation in the Scottish electronics industry, Industrial Management and Data Systems, 95(9), 17-22.

24. Gupta, A. K. (2012). Just in time revisited: literature review and agenda for future research, International Journal of Research in Mechanical Engineering \& Technology, 2(1), 59-63.

25. Cannon, A. (2008). Inventory improvement and financial performance, International Journal of Production Economics, 115(2), 581-593.

26. Thomas, D., \& Griffin, M. (1996). Coordinated supply chain management, European Journal of Operational Research, 94(1), 1-15.

27. Barney, J. (1991). Firm resource and sustained competitive advantage, Journal of Management, 17(1), 99-120.

28. Wernerfelt, B. (1984). A resource-based view of the firm. Strategic Management Journal, 5(5), 171-180.

29. Teece, D., Pisano, G., \& Shuen, A. (1997). Dynamic capabilities and strategic management, Strategic Management Journal, 18, 509-533.

30. Conner, K. (1991). Historical comparison of resource-based theory and five schools of thought within industrial organization economics: Do we have a new theory of the firm?. Journal of Management, 17(1), 121-154.

31. Barney, J. (2002). Gaining and Sustaining Competitive Advantage, Second Edition, Prentice Hall, NJ.

32. Amit, R., \& Schoemaker, P. J. (1993). Strategic assets and Organizational rent, Strategic Management Journal, 13, 33-46.

33. Madhani, M. P. (2010). Resource Based View (RBV) of Competitive Advantage: An Overview. Retrieved at http://ssrn.com/abstract $=1578704$

34. Cainelli, G., De Marchi, V., \& Grandinetti, R. (2015). Does the development of environmental innovation require different resources? Evidence from Spanish manufacturing firms. Journal of Cleaner Production, 94, 211-220.

35. Conner, K. R., \& Prahalad, C. K. (1996). A Resource-Based Theory of the Firm: Knowledge vs. Opportunism. Organization Science, 7, 477-501. http://dx.doi.org/10.1287/orsc.7.5.477

36. Hill, W. L., Jones, G. R., Galvin, P., \& Haidar. A. (2007). Strategic Management: an Integrated Approach, John Wiley and Sons, Australia.

37. Prahalad, C. K., \& Hamel, G. (1990). The core competence of the corporation, Harvard Business Review, 68(3), 7991.

38. Penrose, E. T. (1959). The Theory of the Growth of the Firm, Blackwell, Oxford.

39. Dierickx, I., \& Cool, K. (1989). Asset stock accumulation and sustainable competitive advantage. Management Science, 35, 1504-1511.

40. Ahuja, G., \& Katila, R. (2004). Where do resources come from? The role of idiosyncratic situations, Strategic Management Journal, 25(8-9), 887-907.

41. Brumagim, A. (1994). A hierarchy of corporate resources. In: P. Shrivastava, A. Huff and J. Dutton (eds), Advances in Strategic Management, Vol. 10 Part A, Resource-based view of the firm, pp. 81-112.

42. Peteraf, M. A. (1993). The cornerstones of competitive advantage: A resource-based view, Strategic Management Journal, 14, 179-191.

43. Cool, K., Almeida Costa, L., \& Dierickx, I. (2002). Constructing Competitive Advantage in Pettigrew, Andrew, Thomas, Howard and Whittington, Richard (Eds), Handbook of Strategy and Management. 
44. Hobday, M., \& Davies, A. (2015). The Business of Projects: Managing Innovation in Complex Products and Systems. https://doi.org/10.1017/CBO9780511493294

45. Ogu, M. I. (2013). Rational Choice Theory: Assumptions, Strenghts, And Greatest Weaknesses In Application Outside The Western Milieu Context. Arabian Journal Of Business And Management Review (Nigerian Chapter), 1(3), 90-99.

46. Scott, S. G., \& Bruce, R. A. (1995). Decision making style: the development and assessment of a new measure. Education Psychology Management. 55:818-831.

47. Oliveira, A. (2007). A discussion of rational and psychological decision making theories and models: the search for a cultural ethical decision making model. Electron J Bus Electron J Bus Ethics Org Stud. 12(2):12-17.

48. Blume, L. E., \& Easly, D. (2008). The New Palgrave Dictionary of Economics, Second Edition. Palgrave, Macmillan. Retrieved from http://www.dictionaryofeconomics.com/ Article

49. Sen, A. (2008). The discipline of economics. Economic, 75(300):617-628.

50. Fred, C. (2010). The decision making process. National Forum of educational administration and supervision journal, 27(4).

51. Rubinstein, A. (1999). Modellin Bounded Rationality. Journal of economics, 70(1), 92-95.

52. Little, D. (1991). Rational-Choice Models and Asian Studies. Rational-Choice Models and Asian Studies, 50(1), $35-$ 52. Available online at: http://www.jstor.org/stable/2057474.

53. Leoveanu, A. C. (2013). Rationalist Model in Public Decision Making. Journal of Public Administration, Finance and Law. (4), 43-54.

54. Simon, H. (1979). Rational decision-making in business organizations. The American Economic Review, 69(4), 4935413.

55. Marshall, G. (1998, March 12). Satisficing. Retrieved from A dictionary of sociology: http://www.encyclopedia.com/doc/1088-satisficing.html.

Citation: Asikhia, A et al (2021). Integrating Just in Time Theory, Resource Based View Theory, and Rational Choice Theory in Enhancing Managements’ Efficiency. South Asian Res J Bus Manag, 3(1), 14-22. 